\title{
Networked Spin Cages: Tunable Magnetism and Lithium- ion Storage via Modulation of Spin-electron Interactions
}

Guo-Hong Ning, ${ }^{\dagger}$ Bingbing Tian, ${ }^{\dagger, 9}$ Li-Min Tan, ${ }^{\dagger}$ Zijing Ding, ${ }^{\dagger, \uparrow}$ Tun Seng Herng, ${ }^{\ddagger}$ Jun Ding, ${ }^{\dagger}$ Kian Ping Loh ${ }^{*}, \dagger$

${ }^{\dagger}$ Department of Chemistry, National University of Singapore, 3 Science Drive 3, Singapore 117543, Singapore

Department of Materials Science \& Engineering, Faculty of Engineering, National University of Singapore, 7 Engineering Drive 1, Singapore 117574, Singapore

${ }^{\circledR}$ SZU-NUS Collaborative Innovation Center for Optoelectronic Science \& Technology, Key Laboratory of Optoelectronic Devices and Systems of Ministry of Education and Guangdong Province, College of Optoelectronic Engineering, Shenzhen University, Shenzhen 518060, China. 


\section{Contents}

1. General procedure

2. Experimental section

2.1 Synthesis of radical ligand 2

2.2 Synthesis and characterization of networked spin cages 1

2.3 Synthesis and characterization of inclusion complex $\mathbf{1 \cdot 3}$ and $\mathbf{1 \bullet 4}$

2.4 X-ray crystallographic data of networked spin cages 1

3. IR spectrum of inclusion complex $\mathbf{1 \bullet 3}$

4. Solid-state UV-vis sperctrum of $\mathbf{1}, \mathbf{1 \bullet 3}$ and $\mathbf{1 \bullet 4}$

5. VT-ESR analysis of $\mathbf{1}, \mathbf{1 \bullet 3}$ and $\mathbf{1 \bullet 4}$

6. Magnetic properties of $\mathbf{1 , 1 \cdot 3}$ and $\mathbf{1 \cdot 4}$

7. Electrochemical properties of $\mathbf{1}, \mathbf{1} \cdot \mathbf{3}$ and $\mathbf{1 \bullet 4}$

8. Calculation Number of Lithium-ion insertion

9. Computational Methods and lithium atom binding model 


\section{General procedure}

All reagents and starting materials were obtained from commercial suppliers and used without further purification. ${ }^{1} \mathrm{H}$ and ${ }^{13} \mathrm{C}$ NMR spectra were recorded on Bruker AV-300 (300 MHz) spectrometers. All NMR spectral data were collected at $300 \mathrm{~K}$, and chemical shifts were reported as the delta scale in parts per million (ppm) relative to an external standard tetramethylsilane (TMS) $\left(\delta=0.00 \mathrm{ppm}\right.$ for ${ }^{1} \mathrm{H}$ and $\left.{ }^{13} \mathrm{C} \mathrm{NMR}\right)$. Elemental $(\mathrm{C}, \mathrm{H}, \mathrm{N})$ analysis was performed on a ElementarVario Micro Cube analyzer. Single crystal X-ray diffraction data were collected on a BRUKER APEX-II CCD diffractometer equipped with a focusing mirror (MoKa radiation $\lambda=0.71073 \AA$ ) and $\mathrm{a} \mathrm{N}_{2}$ generator (Japan Thermal Eng. Co., Ltd.). Infrared spectra were recorded with a Perkin-Elmer Model 1600.

Solid-state UV-Vis absorption was recorded on a SHIMADZU UV-2450 spectrometer. Networked spin cage crystals were grinded into fine powders. The powder was poured into the copper holder plate and was pressed well. The barium sulphate $\left(\mathrm{BaSO}_{4}\right)$ paster was used as reference.

ESR spectra were recorded with a JEOL JES-FA200 spectrometer with X-band microwave. Magnetic field was calibrated with the $\mathrm{Mn}^{2+} / \mathrm{MnO}$ standard. The Mn marker consists of six signals and the third of fourth of it are calibrated to account got field variations. Sample solids were dried in oven and charged in a $5 \mathrm{~mm} \phi$ quartz sample tube.

Magnetic susceptibility data were collected using a Quantum Design 7 Tesla SQUID-VSM magnetometer, samples were immersed in solvents while measuring. Microcrystal samples of networked spin cage with a weight of 5-10 mg were sealed in a plastic capsule. Magnetic moment was measured in the temperature range of 2 to $380 \mathrm{~K}$. The empty plastic capsule exhibited diamagnetic and its magnetic moment was measured for correction. After correction of diamagnetic signal of plastic capsule and sample holder, magnetic susceptibility was fitted with Bleaney-Bowers equation:

$$
\chi=N \beta^{2} g^{2} / 3 k T \cdot\left[1+1 / 3 \cdot \exp \left(J_{s-t} / k T\right)\right]^{-1}
$$

Cyclic voltammetry (CV) was performed on an Ivium-n-Stat multi-channel electrochemical analyser. Cyclic voltammograms were recorded in the potential range $1.5-3.5 \mathrm{~V}\left(v s . \mathrm{Li} / \mathrm{Li}^{+}\right)$at a scanning rate of 0.1 $\mathrm{mV} \mathrm{s}-1$, starting from OCP into the cathodic direction.

CR2016-type coin cell batteries were assembled to analyze the electrochemical behaviors. The separator was Whatman Glass Microfibre Filter. The cells were assembled in a glovebox filled with highly pure argon gas, and charge/discharge tests were performed in the voltage range of 1.5 to $3.5 \mathrm{~V}\left(\mathrm{vs} . \mathrm{Li} / \mathrm{Li}^{+}\right)$at current densities of $100 \mathrm{~mA} \mathrm{~g}^{-1}$ on a Land batteries tester. 


\section{Experimental section}

\section{2-1. Synthesis of 1, 3, 5-tri-(4-pyridyl)-verdazyl radical ligand 2}
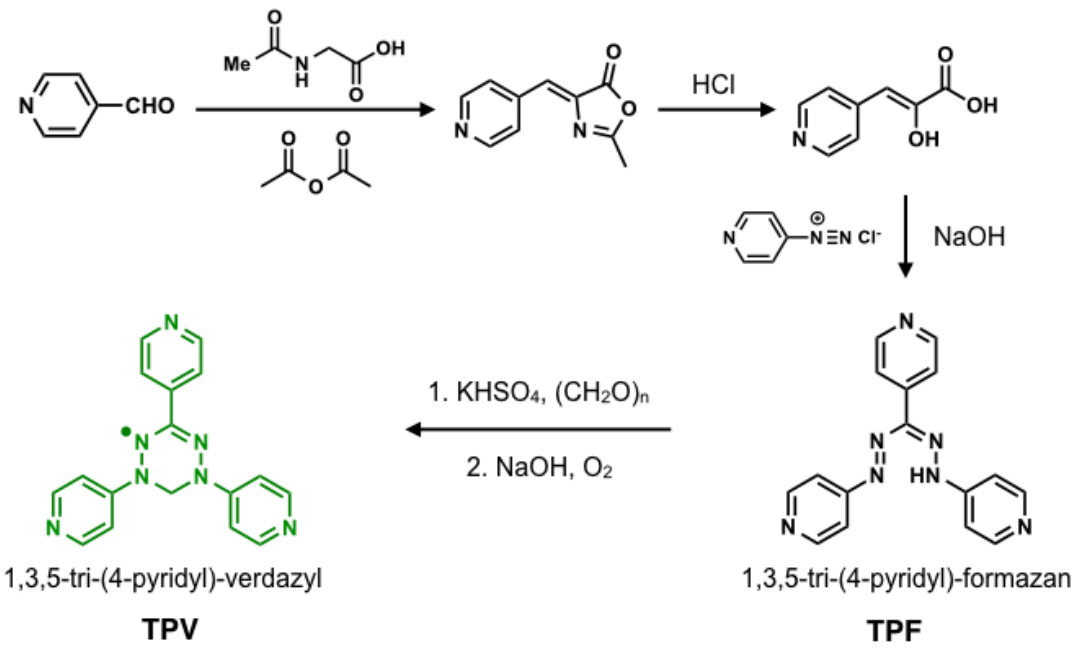

The titled compound was prepared as described in the reported literatures with slight modification. ${ }^{[1]} 1,3,5-$ tri-(4-pyridyl)-formazan (680 mg, $2.24 \mathrm{mmol})$, Paraformaldehyde $(18.2 \mathrm{~g}$ ) and Potassium hydrogen sulfate ( $9.9 \mathrm{~g}, 72.7 \mathrm{mmol}$ ) were stirred for $6 \mathrm{~h}$ in $80 \mathrm{ml} \mathrm{DMF}$ at $\mathrm{r}$. t. The mixture was diluted with $300 \mathrm{ml}$ distilled water, and then, sodium hydroxide $(4 \mathrm{M}, 40 \mathrm{~mL})$ was added, stirred for $24 \mathrm{~h}$ at $\mathrm{r}$. t. with air bubbling. The resultant green solid was filtered, washed with distilled water and dried up in vacuo. The crude solid was purified by column chromatography (eluent: $\mathrm{CHCl}_{3} / \mathrm{MeOH}=15 / 1, R_{\mathrm{f}}=0.4$ ) to give titled compound as a green solid (400 mg) in $56 \%$ yield: ESI-MS m/z calcd for $\mathrm{C}_{17} \mathrm{H}_{14} \mathrm{~N}_{7}: 317.3[\mathrm{M}+\mathrm{H}]^{+}$; found: 317.1 . Elemental Anal. Calcd for $\mathrm{C}_{17} \mathrm{H}_{14} \mathrm{~N}_{7}$ : C, 64.55; H, 4.46; N, 30.99. Found: C, 64.41; H, 4.55; N, 30.82. IR (KBr): 3440 (br), 1585 (s), 1505 (s), 1406 (m), 1376 (m), 1267 (m), 1244 (m), 1156 (m), 992 (m), 810 (s), $610 \mathrm{~cm}^{-1}$ (m). ESR: $g=2.003, \mathrm{a}_{\mathrm{N}}=0.56 \mathrm{mT}$.

\section{2-2. Synthesis of networked spin cages 1}

A solution of 1, 3, 5-tri-(4-pyridyl)-verdazyl radical ligand $2(6.3 \mathrm{mg}, 0.02 \mathrm{mmol})$ in a $4 \mathrm{~mL}$ dichlorobenzene and $1 \mathrm{~mL} \mathrm{MeOH}$ mixture was placed in the bottom of a test tube (inner diameter $1 \mathrm{~cm}$, height $10 \mathrm{~cm}$ ).
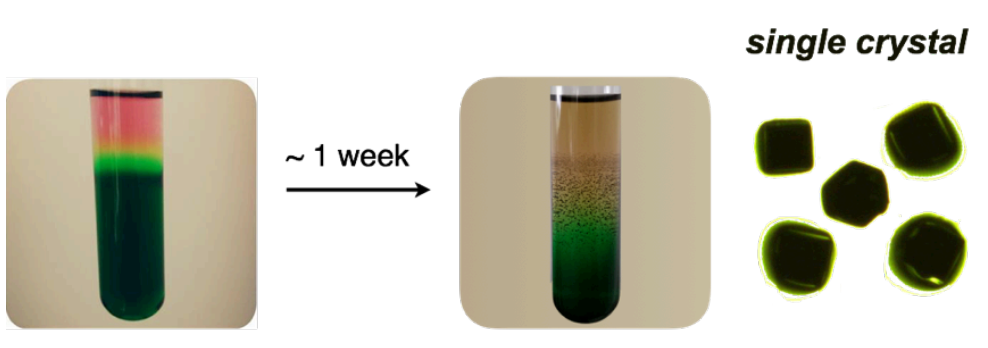

$\mathrm{MeOH}(1 \mathrm{~mL})$ was layered on the top of the reaction mixture as a buffer. After then, a solution of $\mathrm{Co}(\mathrm{NCS})_{2}(7.0 \mathrm{mg}, 0.04 \mathrm{mmol})$ in methaol $(1 \mathrm{~mL})$ was carefully layered on the top of the resultant solution, and the test tube was allowed to stand at room temperature (RT) for $\sim 1$ week (shown as

left figure). The networked spin cage $\mathbf{1}$ was produced as dark-green cubic crystals on the surface of the test tube and was collected, filtrated and dried at $120{ }^{\circ} \mathrm{C}$ under reduced pressure for 1 day. (64\% yield, $6 \mathrm{mg}$; averaged value over 3 batches). IR (KBr): 3421 (m), 3050 (m), 2060 (s, SCN), 1654 (m), 1599 (s), 1502 (s), 
$1408(\mathrm{~m}), 1375$ (s), $1218(\mathrm{~m}), 1148(\mathrm{~m}), 1013(\mathrm{~m}), 821 \mathrm{~cm}^{-1}(\mathrm{~m})$. Elemental analysis: calculated for $\left\{\left[\mathrm{Co}(\mathrm{NCS})_{2}\right]_{3}(2)_{4}\left(\mathrm{C}_{6} \mathrm{H}_{4} \mathrm{Cl}_{2}\right)_{0.5}\right\}_{\mathrm{n}}$ : C 49.61, H 3.14, N 25.55; found : C 49.51, H 3.11, N 25.58. Notably, the crystals were carefully washed with mix solvent (dichlorobenzene/ $\mathrm{MeOH}=4 / 1$ ) to remove magnetic impurity, likely unreacted $\mathrm{Co}(\mathrm{NCS})_{2}$.

\section{2-3. Synthesis of inclusion complexes.}

As-synthesized $1(\sim 100 \mathrm{mg})$ was immersed in a toluene solution of guest molecules (i.e. tetracyanoethylene (3) and tetrathiafulvalene (4)) $(2 \mathrm{~mL})$ and allowed to stand at room temperature for $5 \mathrm{~d}$ during which the supernatant was replaced three times with a freshly prepared solution of guest by decantation. The crystals were separated and collected by filtration and washed with toluene to give the inclusion complex $\mathbf{1 \bullet 3}$ or $\mathbf{1 \bullet 4}$.

Inclusion complex 1•3: Elemental analysis: calculated for $\left\{\left[\left(\mathrm{Co}(\mathrm{NCS})_{2}\right)_{3}(\mathbf{2})_{4}\right] \bullet(3)_{5}\right\}_{n}$ : C 51.25, H 2.38, N, 30.77; found: C 51.22, H 2.37, N 30.79. IR (KBr): 3381 (m), 3061 (m), 2072 (s, SCN st), 1723 (s, C=O st), 1586 (s), 1528 (s), 1479 (m), 1423 (m), 1365 (s), 1319 (m), 1195 (m), $1029 \mathrm{~cm}^{-1}$ (m).

Inclusion complex 1•4: Elemental analysis: calculated for $\left\{\left[\left(\mathrm{Co}(\mathrm{NCS})_{2}\right)_{3}(\mathbf{2})_{4}\right] \bullet(\mathbf{4})_{2.5}\right\}_{n}$ : C 46.35, H 3.10, N, 20.65; found: C 46.36, H 3.12, N 20.62. IR (KBr): 3391 (m), 3063 (m), 2978 (m), 2065 (s, SCN st), 1719 (s, $\mathrm{C}=\mathrm{O}$ st), 1587 (s), 1526 


\section{2-4. X-ray crystallographic data of networked spin cages 1}

\section{Crystallographic data for 1:}

$\mathrm{C}_{26} \mathrm{H}_{16} \mathrm{CoN}_{10} \mathrm{~S}_{2}, M r=591.54$, Cubic Fm-3m, $a=b=c=36.793$ (10) $\AA, V=49808$ (41) $\AA^{3}, T=90(2) \mathrm{K}, Z=$ $24, \rho_{\text {calcd }}=0.473,900$ unique reflections out of 2574 with $I>2 \sigma(I), 58$ parameters, final $R_{I}=0.1486$ and $w R_{2}$ $=0.3790$ for all data. CCDC deposit number 1497717. Residual electron densities in the solvent-accessible void due to disordered solvent molecules were treated with the PLATON SQUEEZE program. (A. L. Spek, Acta Crystallogr., Sect. A: Fundam. Crystallogr., 1990, 46, C34.) Before the treatment of SQUEEZE program; the maximum electron density remained was $2.259, R_{1}=0.3573$ and $w R 2=0.6386$ for all data.

a

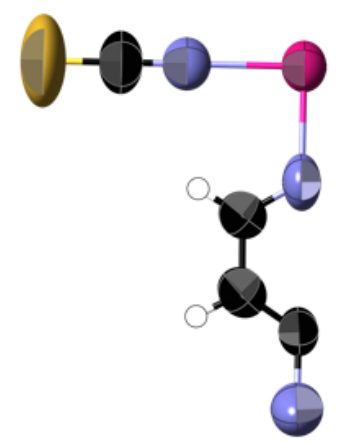

C

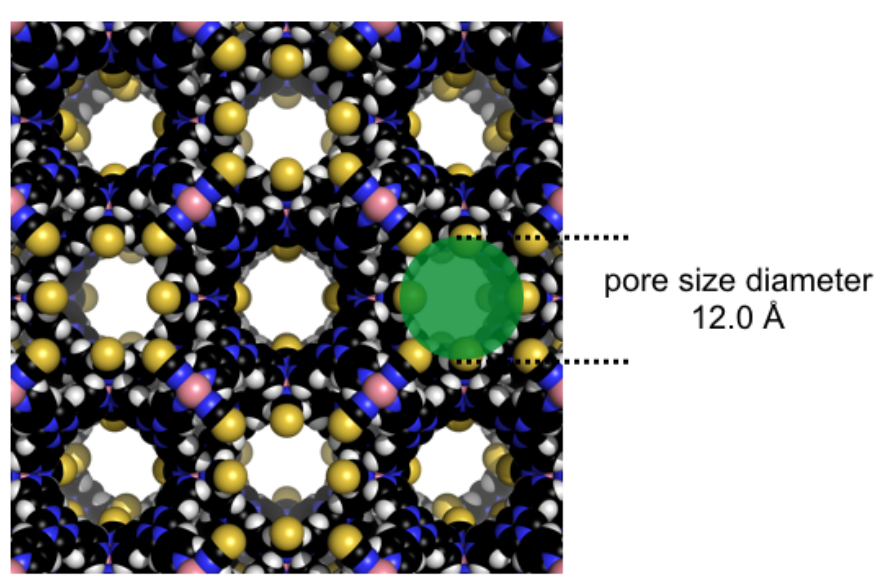

b

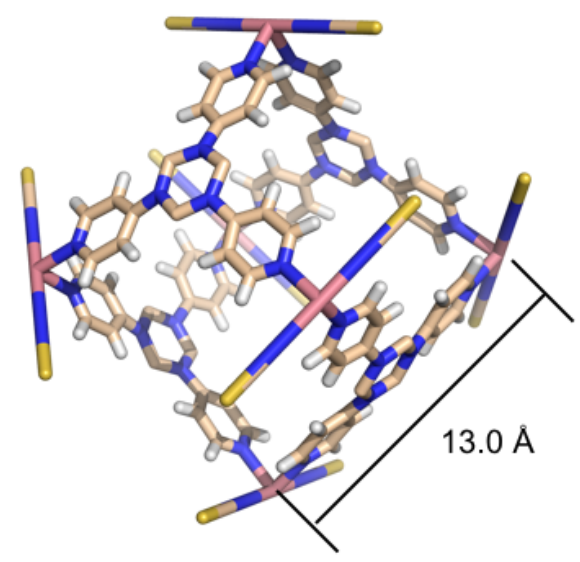

Figure S1. Crystal structure of networked spin cages 1. a) Asymmetric unit is drawn as ellipsoids at $50 \%$ probability. b) One $\mathrm{M}_{6} \mathrm{~L}_{4}$ cage unit showing the distance between two Co(II) ion center; c) networked structures of 1 is drawn as space filling model. 
3. IR spectrum of inclusion complex $1 \cdot 3$

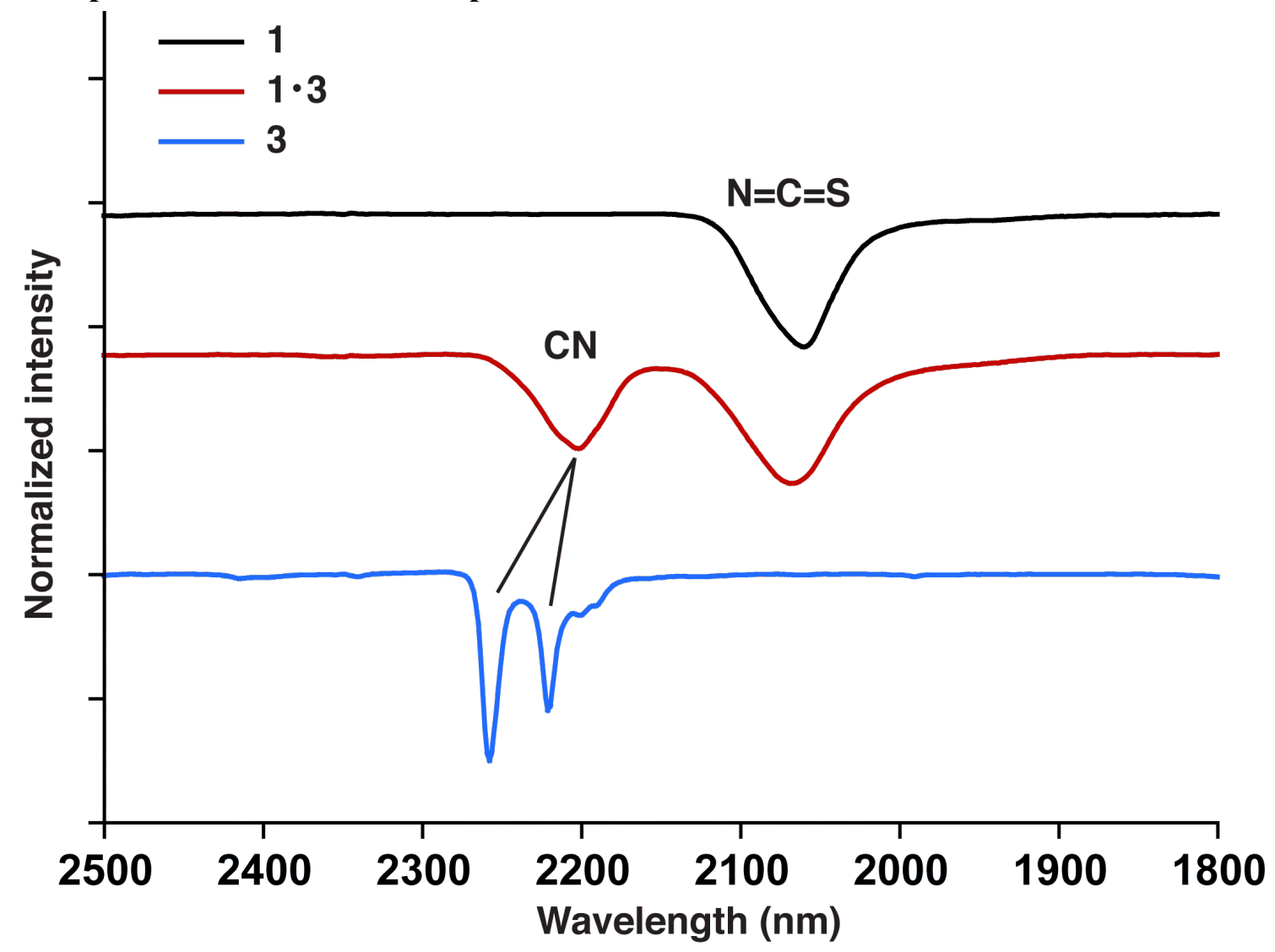

Figure S2. IR spectrum of networked spin cages 1 (black line), inclusion complex $\mathbf{1 \cdot 3}$ (red line) and TCNE guest 3 (only the CN and NCS area are shown). 


\section{Solid-state UV-vis spectra of $1,1 \cdot 3$ and $1 \bullet 4$}

The solid-state UV-vis spectrum of networked spin cages 1 shows two strong absorption bands at 450 and $695 \mathrm{~nm}$, which are red shifted to 464 and $696 \mathrm{~nm}$ for inclusion complex 1•3. On the other hand, the solid-state UV-vis spectrum of TTF-inclusion complex 1.4 exhibits almost the similar absorption bands at 451 and $694 \mathrm{~nm}$, which is indicative of weak interactions between electron rich host and electron rich guest 4.

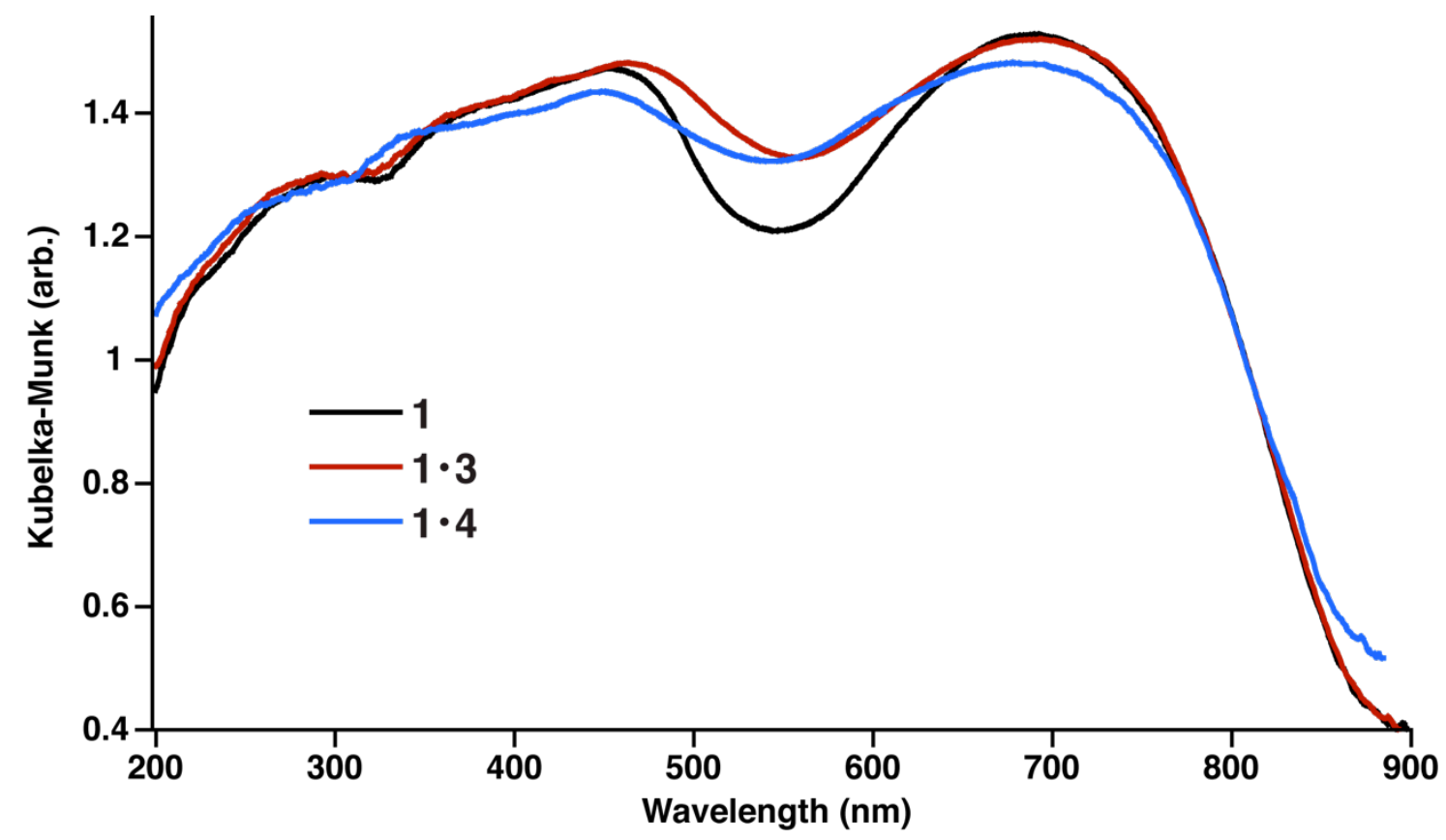

Figure S3. Diffuse reflectance spectra in $\mathrm{BaSO}_{4}$ powder of $\mathbf{1}$ (black), 1•3 (red) and 1•4 (blue). 


\section{VT-ESR analysis of $1,1 \bullet 3$ and $1 \bullet 4$}

We analyzed an ESR spectrum of networked spin cage $\mathbf{1}$ as microcrystalline powder sample to confirm the existence of the radical species. The radical ligand $\mathbf{2}$ shows split signals due to four nitrogen nuclei, while the networked spin cages 1 existed a broad signal. In general, line broadening stems from motional broadening and electron-spin exchange. If the cause is motional broadening, the broad signal should gradually become the nine split signals similar to a ligand according to heating. However, the configuration of ESR spectra in networked spin cages $\mathbf{1}$ is identical (not split) even at $50{ }^{\circ} \mathrm{C}$ (Figure S5). Thus, this broadening is owing to dipolar interaction and/or relatively strong exchange interaction compared to the hyperfine interaction $\left(\mathrm{a}_{\mathrm{N}}=0.56 \mathrm{mT}\right)$.

a)

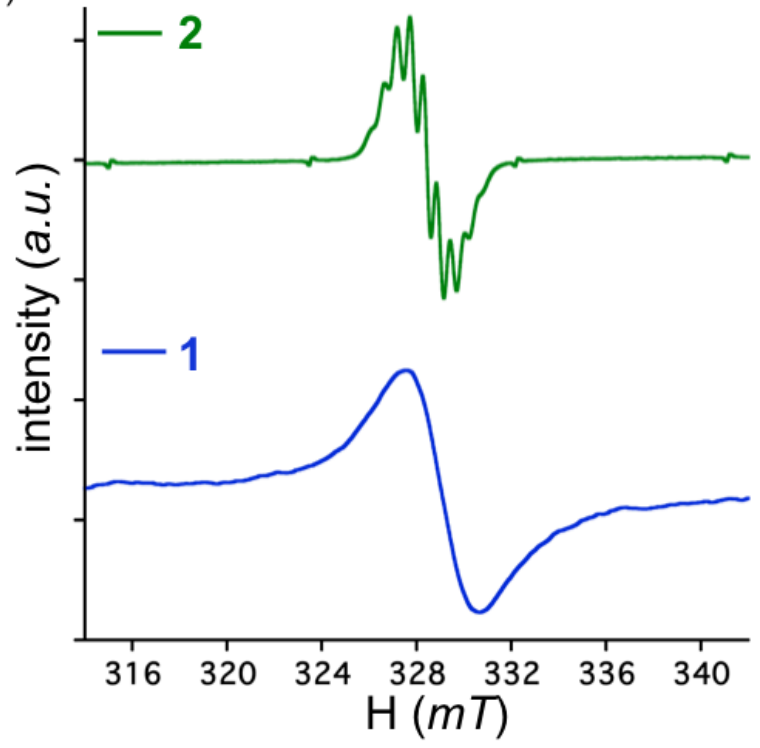

b)

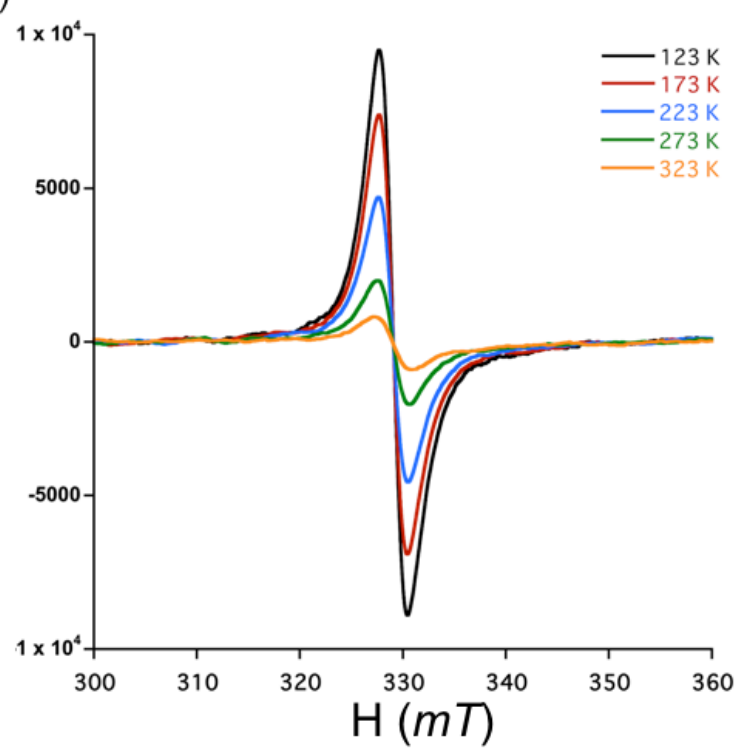

Figure S4. a) Comparison of radical ligand 2 (in $\mathrm{MeOH}$ ) and networked spin cages 1 in solid-state at r.t.; b) VT-ESR analysis of networked spin cages 1 as microcrystalline powder form (from $123 \mathrm{~K}$ to $323 \mathrm{~K})$. 
a
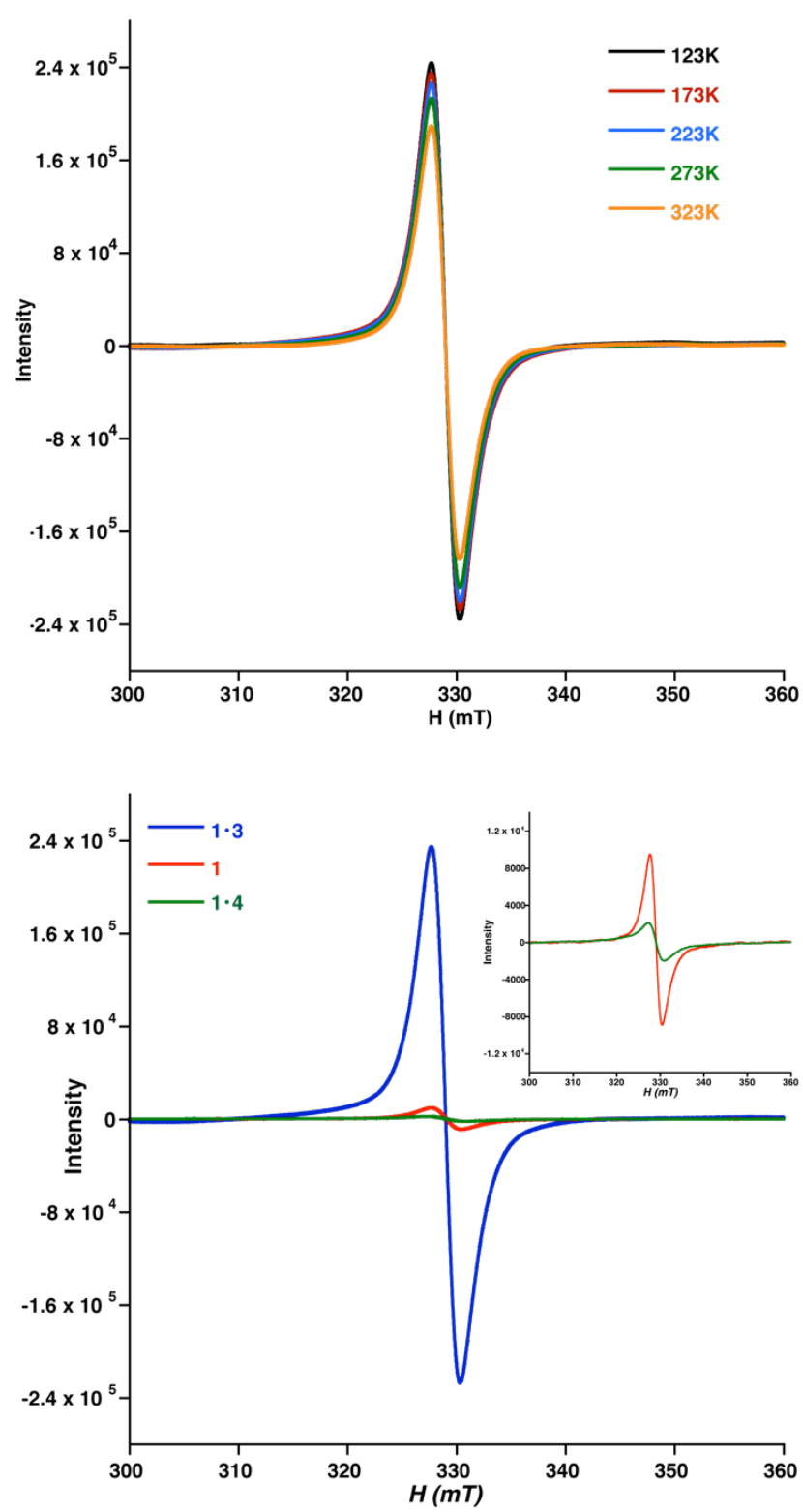

b

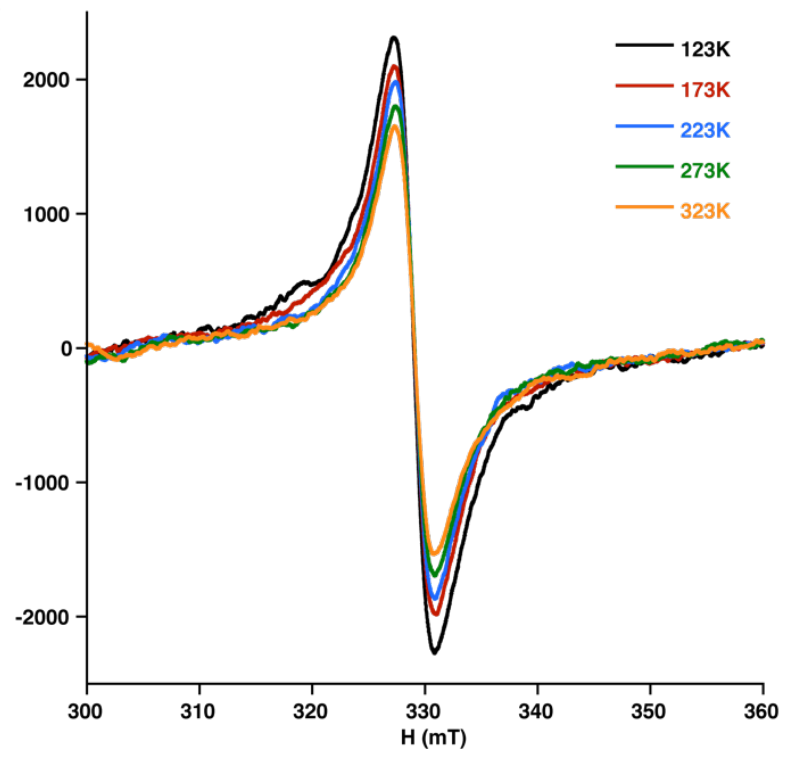

d

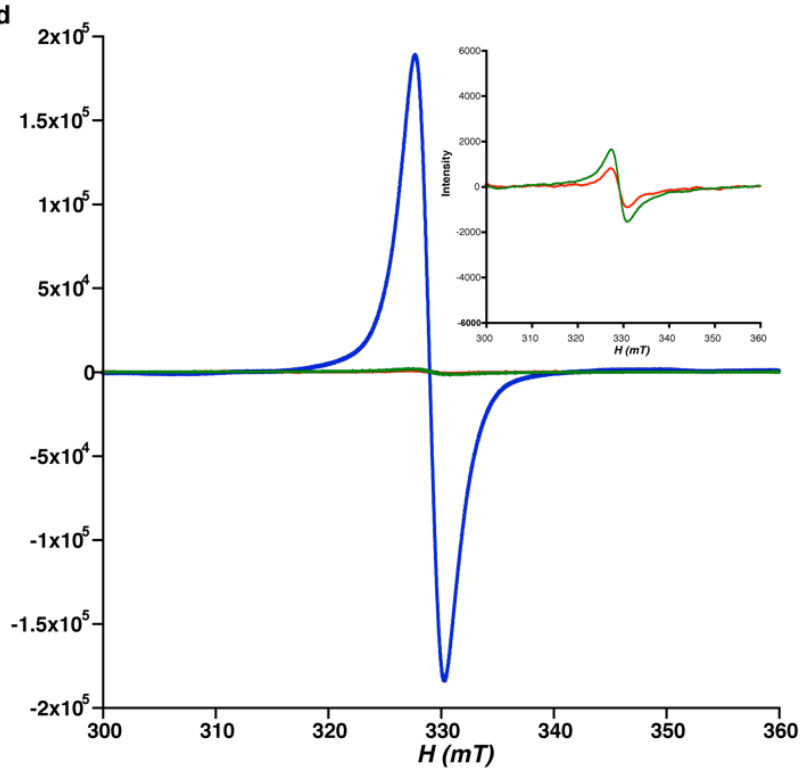

Figure S5. VT-ESR analysis of (a) inclusion complex $\mathbf{1 . 3}$ and (b) $\mathbf{1 . 4}$ as microcrystalline powder form (from $123 \mathrm{~K}$ to $323 \mathrm{~K}$ ); Comparison of ESR intensity at (c) $123 \mathrm{~K}$ and (d) $323 \mathrm{~K}$; inset, ESR signal of 1 and $\mathbf{1 . 4}$ magnified by 20 times (blue, 1•3; red, 1; green, 1•4). 


\section{Magnetic properties of $1,1 \cdot 3$ and $1 \bullet 4$}

a

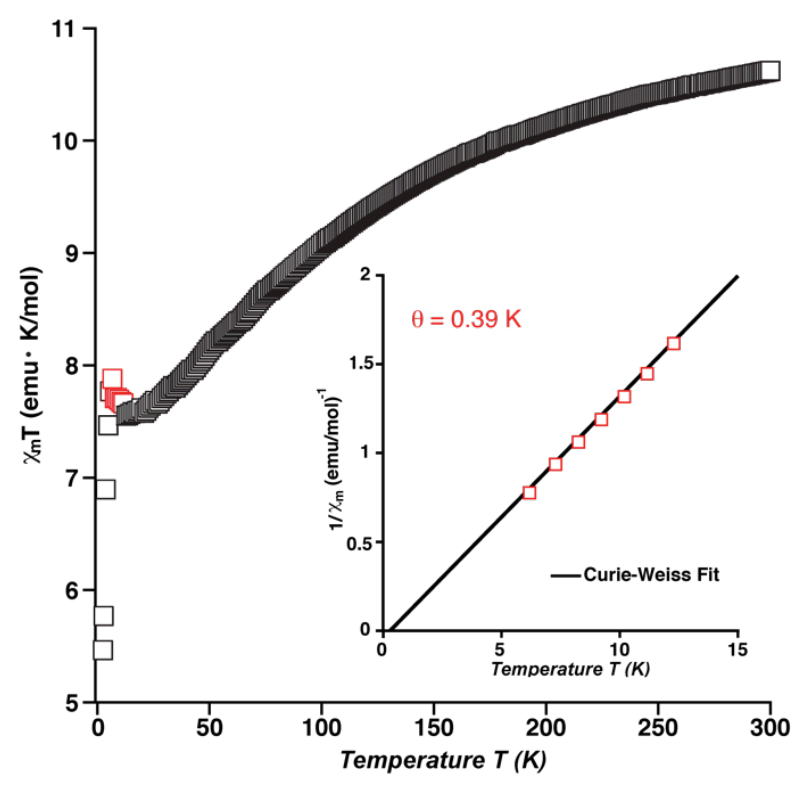

b

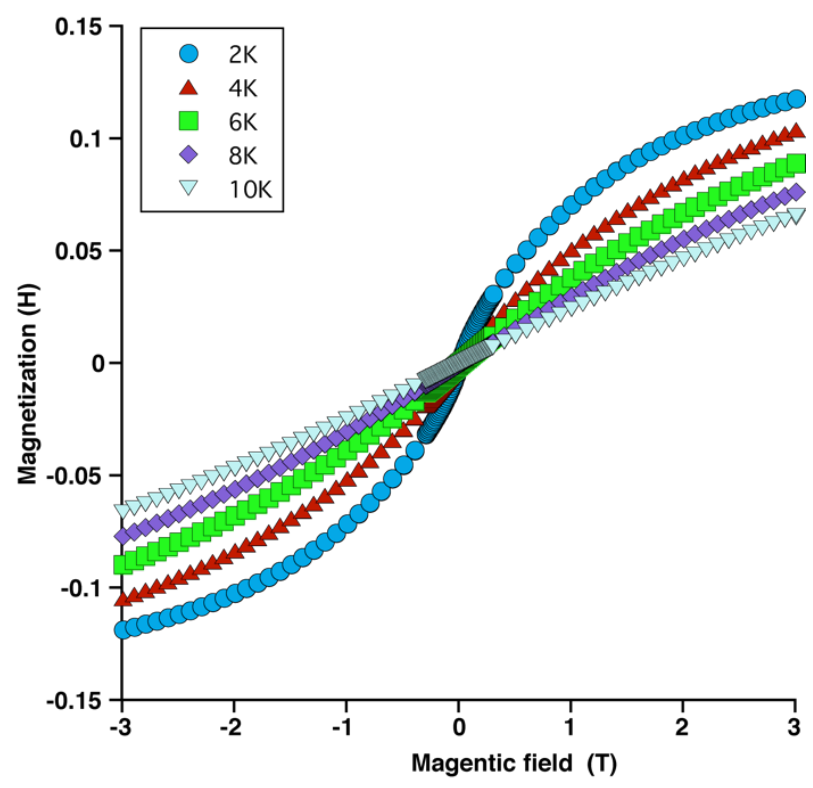

Figure S6. (a) The profile of molar magnetic susceptibility with temerature $\left(\chi_{m} T\right)$ versus temperature for networked spin cages 1 at $\mathrm{H}=5000$ Oe (the slight increased part was highlighted with red color from 6 to $12 \mathrm{~K}$ ); inset, the temperature dependence of inversed molar magnetic susceptibility $\left(1 / \chi_{m}\right)$ of 1 , which are well fitted to Curie-Weiss law from 6 to $12 \mathrm{~K}$, indicating the ferromagneticlly coupled interactions. (b) Magnetization (M) versus applied dc magnetic field $(H)$ profile for 1 at field range of -3 to $3 \mathrm{~T}$ (Below $10 \mathrm{~K}$ the hysteresis loops was observed). 
The profile of molar magnetic susceptibility with temperature $\left(\chi_{\mathrm{m}} T\right)$ versus temperature reveals the room temperature (r.t.) $\chi_{\mathrm{m}} T$ value of $\mathbf{1 . 4}$ is 9.09 emu K mol$^{-1}$. It is slight lower than that of host 1 (10.67 emu K mol${ }^{-1}$ ) and still higher thanthe expected spin-only value of $7.13 \mathrm{emu} \mathrm{K} \mathrm{mol}^{-1}$ calculated for three Co(II) ions and four TPV radicals with $g=2.0$ and local spin $\mathrm{S}_{\mathrm{Co}}=3 / 2$ and $\mathrm{S}_{\mathrm{TPV}}$ $=1 / 2$, respectively. It is indicative of the weak influence of electron-rich guests on the magnetic properties of networked spin cages 1 .

a

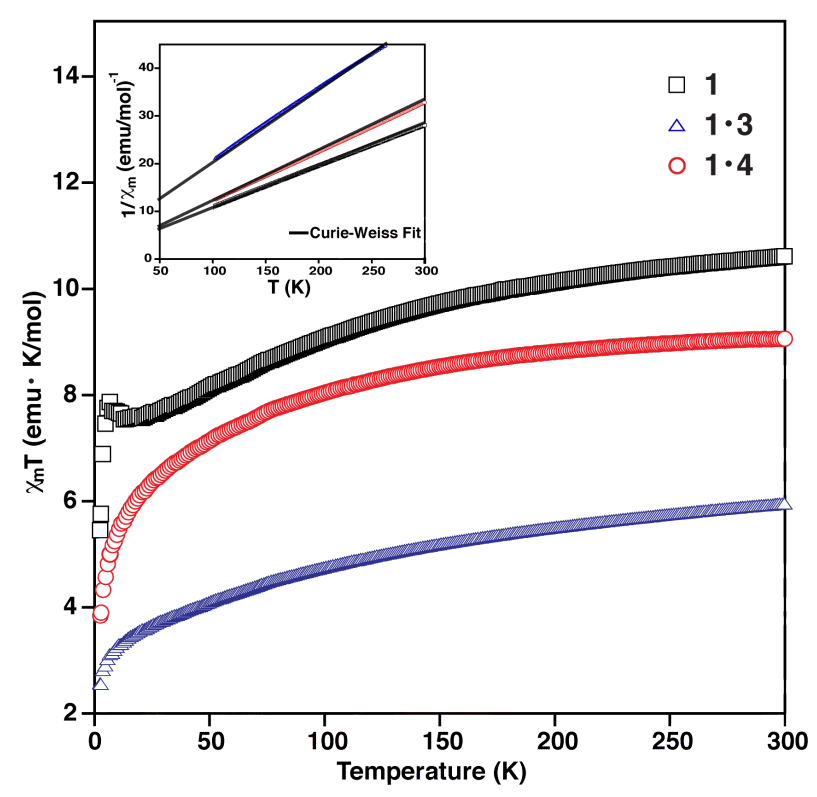

c

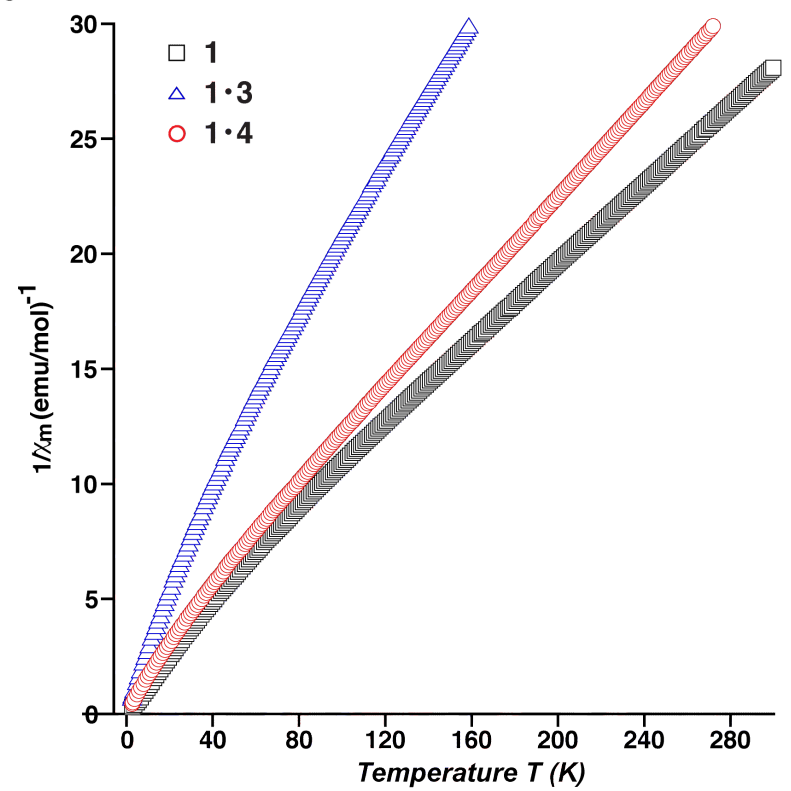

b

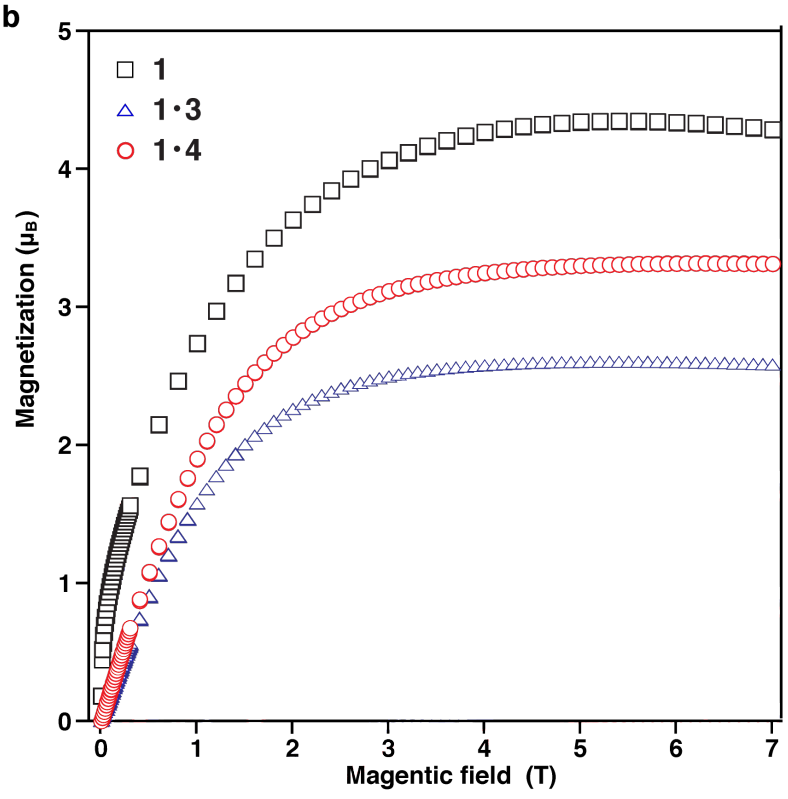

d

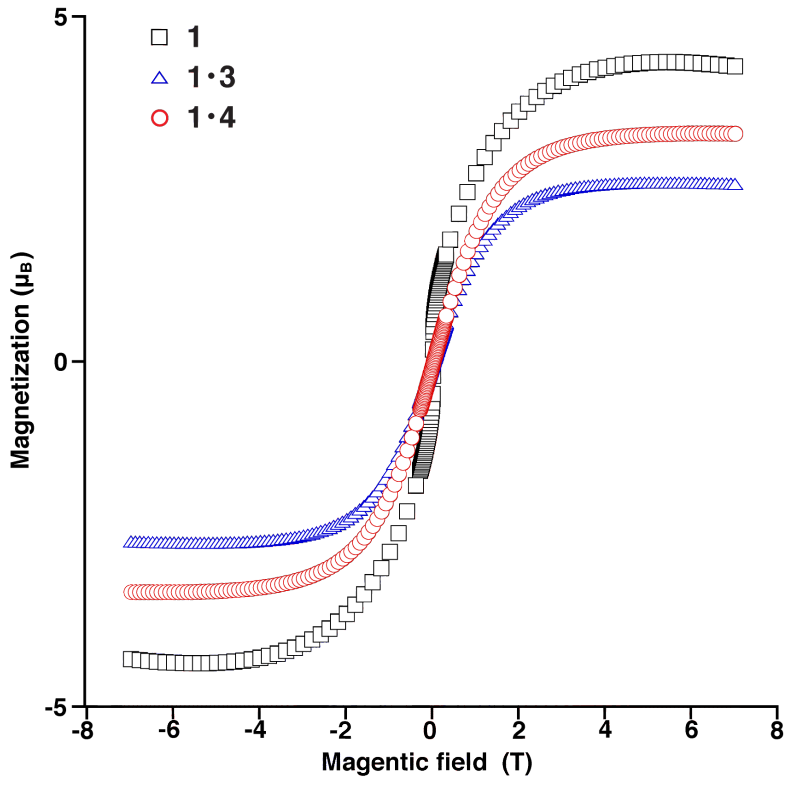

Figure S7. (a) The profile of molar magnetic susceptibility with temerature $\left(\chi_{m} T\right)$ versus temperature for $\mathbf{1}, \mathbf{1 . 3}$ and $\mathbf{1 . 4}$ at $\mathrm{H}=5000 \mathrm{Oe}$; inset, the temperature dependence of inversed molar magnetic susceptibility $\left(1 / \chi_{m}\right)$ of $\mathbf{1}, \mathbf{1 . 3}$ and $\mathbf{1 \cdot 4}$, which are well fitted to Curie-Weiss law from 100 to $300 \mathrm{~K}$. (b) Magnetization $(\mathrm{M})$ versus applied dc magnetic field $(\mathrm{H})$ profile for $\mathbf{1 , 1 \cdot 3}$ and $\mathbf{1 \cdot 4}$ at $2 \mathrm{~K}$ in black, blue and red, respectively. (c) The temperature dependence of inversed molar magnetic susceptibility $\left(1 / \chi_{\mathrm{m}}\right)$ of $\mathbf{1}, \mathbf{1 . 3}$ and $\mathbf{1 . 4}$ at $\mathrm{H}=5000 \mathrm{Oe}(\mathrm{d})$ Magnetization $(\mathrm{M})$ versus applied dc magnetic field $(\mathrm{H})$ profile for $\mathbf{1}, \mathbf{1 . 3}$ and $\mathbf{1 . 4}$ at field range of -7 to $7 \mathrm{~T}$ (at $2 \mathrm{~K}$ ). 
7. Electrochemical properties of TPV, 1, 1•3 and $1 \cdot 4$

a

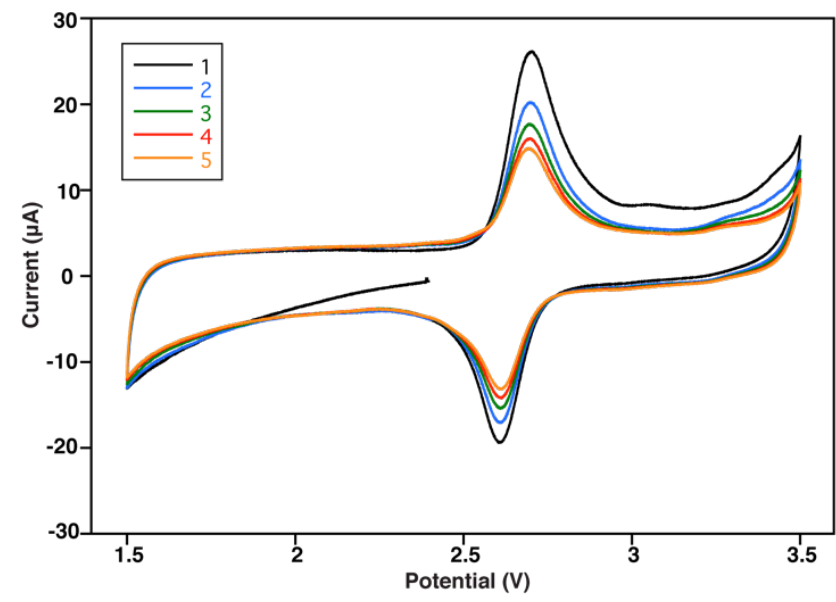

C

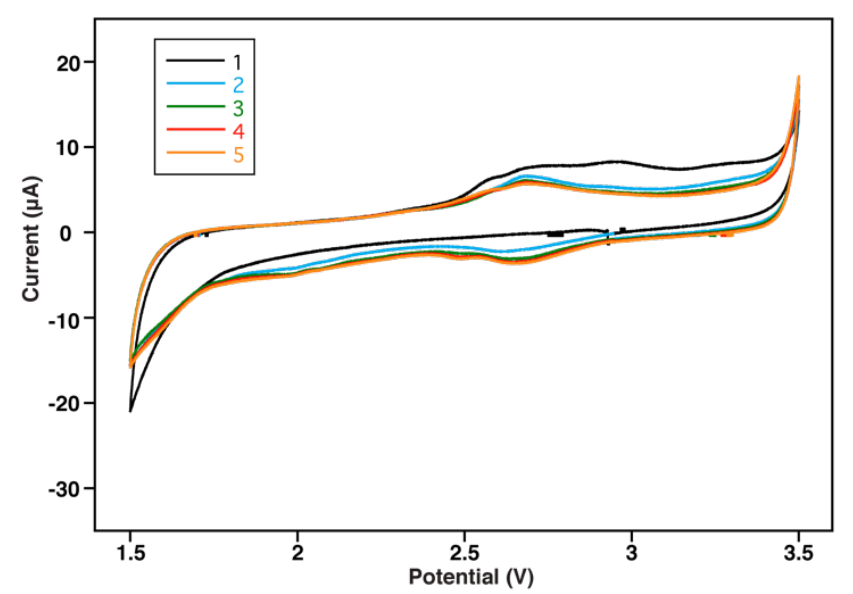

b

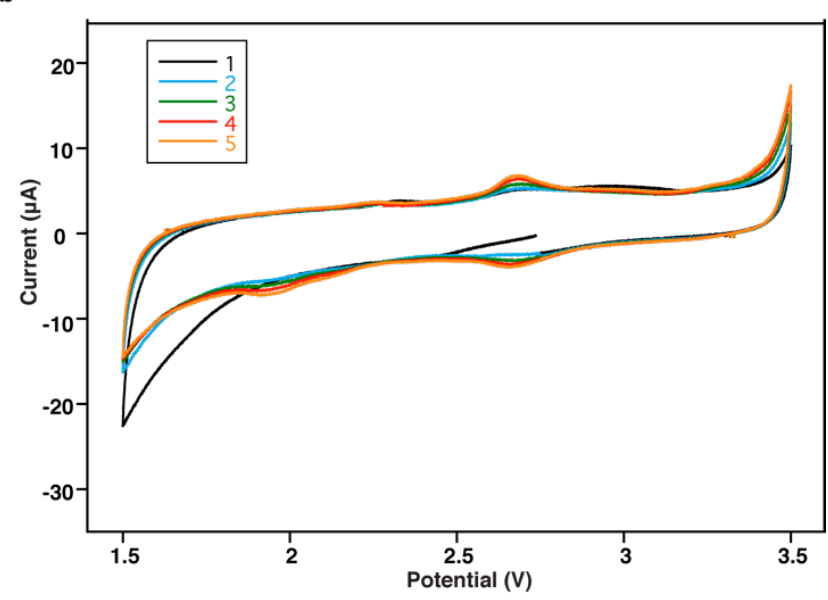

d

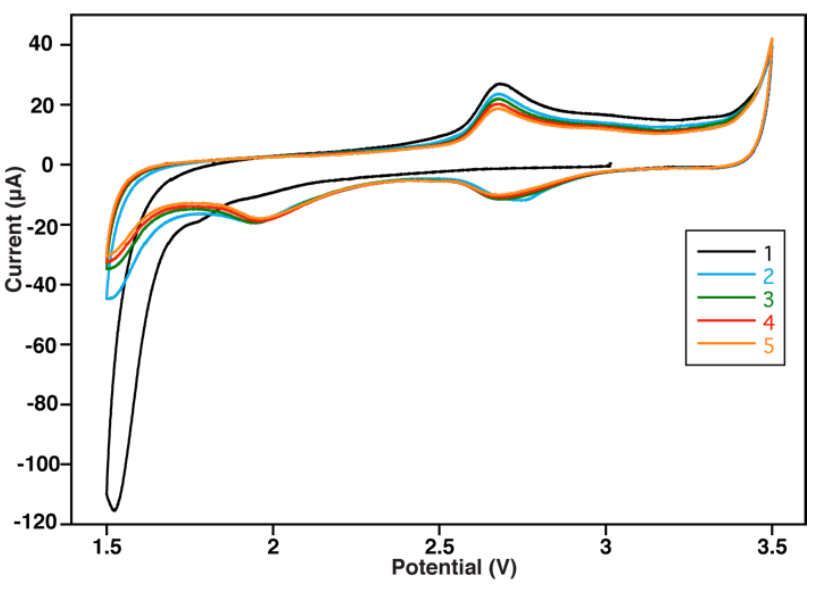

Figure S8. Cyclic voltammograms of the (a) TPV ligand 2; (b) networked spin cages 1; (c) inclusion complex $\mathbf{1 \cdot 3}$; (d) $\mathbf{1 \cdot 4}$ at scan rate of $0.1 \mathrm{mV} \mathrm{s}^{-1}$. 

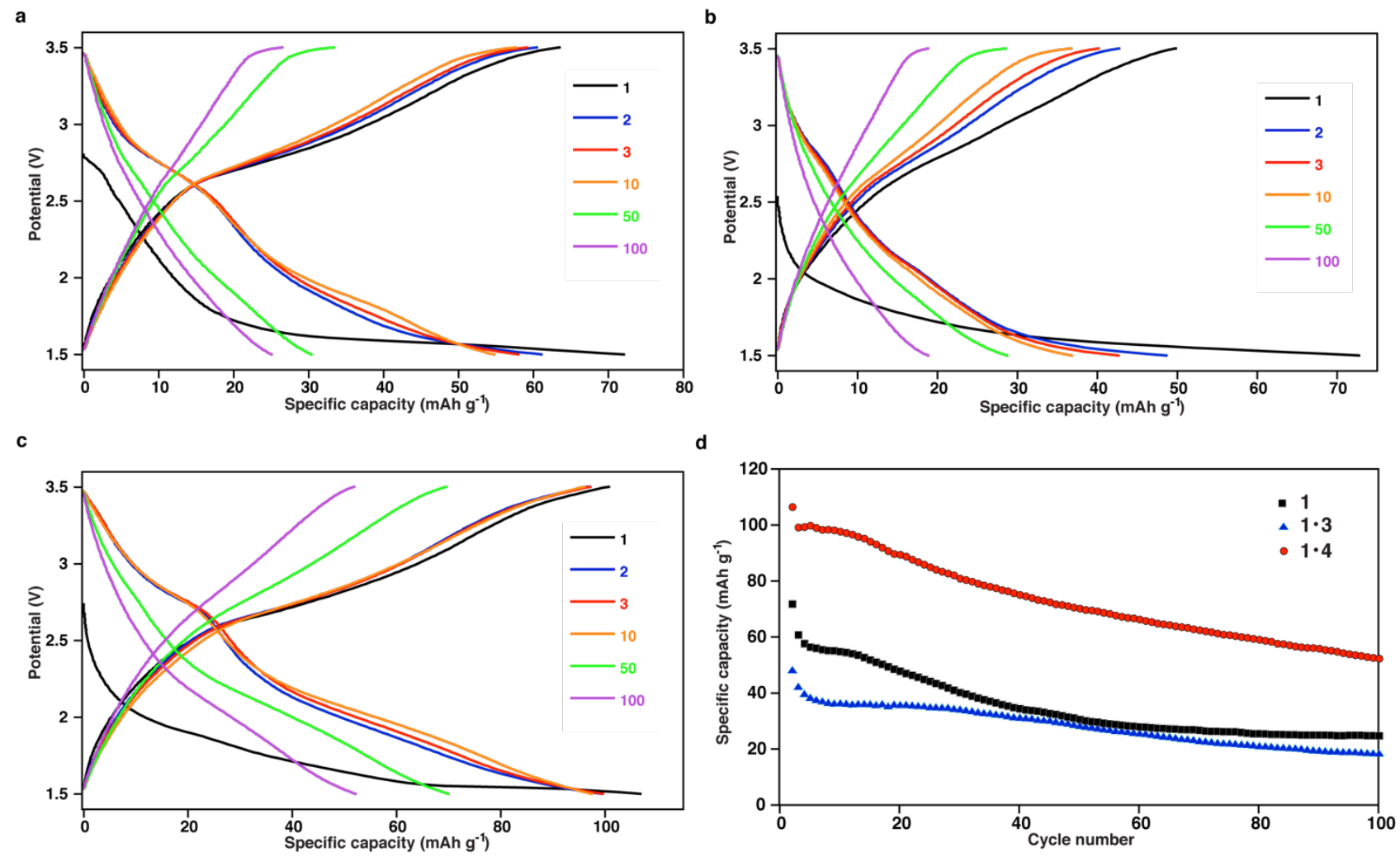

Figure S9. Charge-discharge performance of (a) networked spin cages 1; (b) inclusion complex $1 \cdot 3$; (c) $1 \cdot 4$; and (d) cycling performance of $1,1 \cdot 3$ and $1 \cdot 4$

\section{Calculation number of lithium-ion insertion}

The theoretical specific capacity of as-prepared $\mathbf{1}$ was calculated by the following method:

From the EA data, The formula of 1 could be written as: $\left\{\left[\mathrm{Co}(\mathrm{NCS})_{2}\right]_{3}(2)_{4}\left(\mathrm{C}_{6} \mathrm{H}_{4} \mathrm{Cl}_{2}\right)_{0.5}\right\}_{\mathrm{n}}$, the molecular weight is $1864.16 \mathrm{~g} / \mathrm{mol}$.

$$
\begin{aligned}
\mathrm{C} & =\mathrm{n} \times e \times \mathrm{N}_{\mathrm{A}} /(3.6 \times \mathrm{M} . \mathrm{W} .) \\
& =4 \times 1.602 \times 10^{-19} \times 6.02 \times 10^{23} /(3.6 \times 1864.16)=61.4 \mathrm{mAh} \mathrm{g}^{-1}
\end{aligned}
$$

(n, the number of accepted electron per formula, $e$, quantity of electric charge, NA, Avogadro's number, M.W., molecular weight of 1. 1/(3.6) is the converting factor between Coulomb and mAh unit.)

Thus, the number of lithium-ion insertion can be calculated as following equation: $x=\mathrm{n} \times$ specific capacity/theoretical capacity $=1 \times 61 \mathrm{mAh} \mathrm{g}^{-1} / 61.4 \mathrm{mAh} \mathrm{g}^{-1}=1$

According to the similar method, the number of lithium-ion insertion in inclusion complex 1.4 can be calculated as $x=2$ 


\section{Computational Methods and lithium atom binding model}

The first-principles calculations were carried out within the framework of spin-polarized functional theory, employing Projector augmented wave pseudopotentials ${ }^{2,3}$ and the Perdew-Burke-Ernzerholf form $^{4}$ of the exchange-correlation functional, as implemented in the Vienna ab initio simulation package code. ${ }^{5}$ We employ an energy cutoff of $400 \mathrm{eV}$ for plane waves, and the criterion for total energy convergence is set to $10^{-4} \mathrm{eV}$. All atoms of the molecules are relaxed during geometry optimization until the magnitude of forces is less than $0.04 \mathrm{eV} / \AA$.

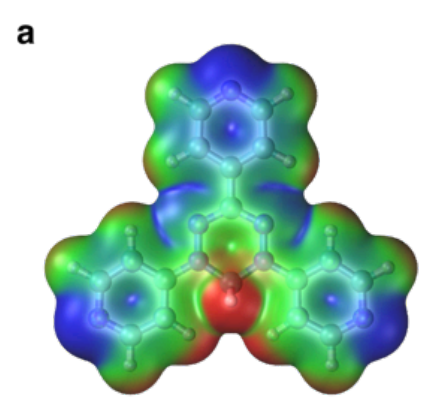

2

b

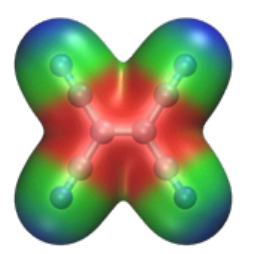

3

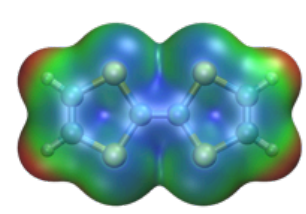

4

Figure S10. Molecular electrostatic potential on the isosurfaces (isovalue of $0.0025 \AA^{-3}$ ) of electron density in molecule (a) 2, (b) 3, (c) 4, which the structures are optimized (the details of DFT calculation see the SI). Red and blue represent positive and negative potential, respectively. The plot scales have been set to the same color scale.

The computed electrostatic potential surfaces of radical ligand $\mathbf{2}$, guests $\mathbf{3}$ and $\mathbf{4}$ provide a qualitative understanding of the host-guest interactions. A strong attractive interaction between the electron-rich part of $\mathbf{2}$ and the electron-deficient guest $\mathbf{3}$ can be expected. Additionally, a relatively weak interaction between the electron-rich p clouds of $\mathbf{4}$ and the electron-poor part of $\mathbf{2}$ can be considered. 
a

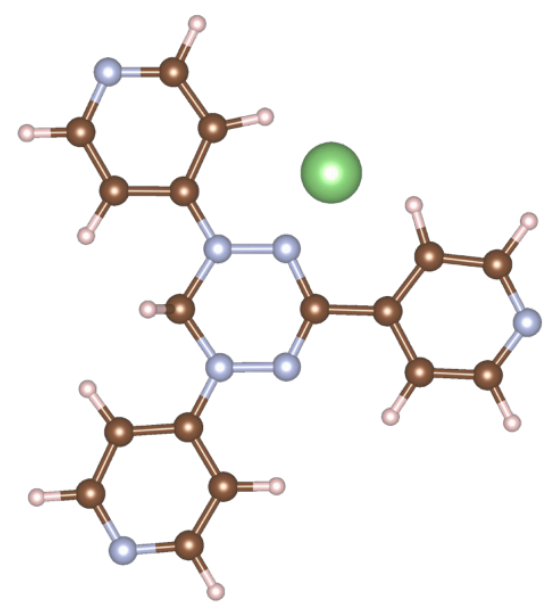

C

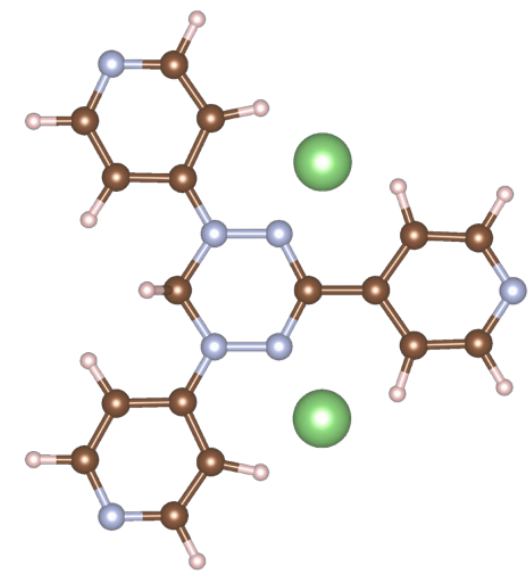

b

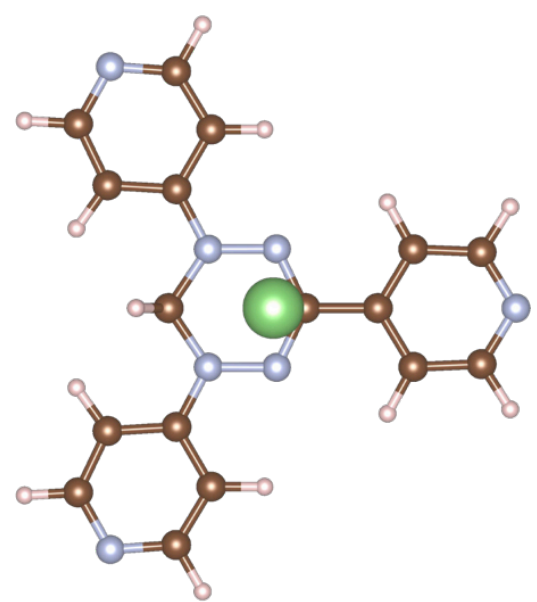

d

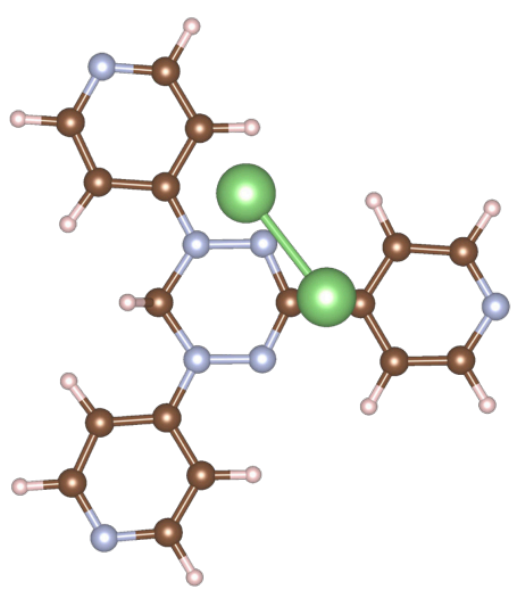

Figure S11. The DFT calculation of lithium atom binding energy with radical ligand $\mathbf{2}$ (the structures are optimized during DFT calculation, details see computational method section).(a) side $\left(E_{b}=2.06 \mathrm{eV}\right)$ and (b) top binding sites with TPV molecule $\left(E_{b}=1.72 \mathrm{eV}\right)$, the binding of second lithium atom with the radical ligand $2(c)$ side $\left(E_{b}=0.70 \mathrm{eV}\right)$ and (d) top binding sites $\left(E_{b}=0.85 \mathrm{eV}\right.$ ) resulting the formation of lithium dimer (the bond length of $L i-L i$ is $2.8 \AA$, which is well agreement with the isolated lithium dimer $(2.67 \AA)$ ). 
a

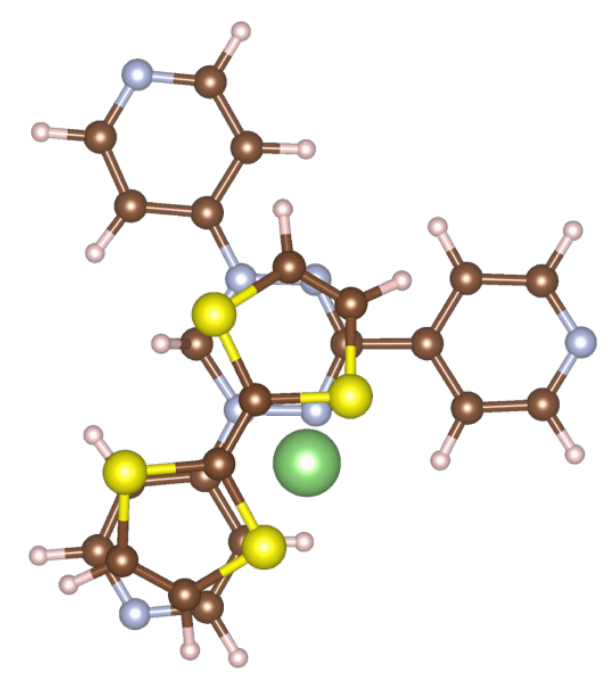

b

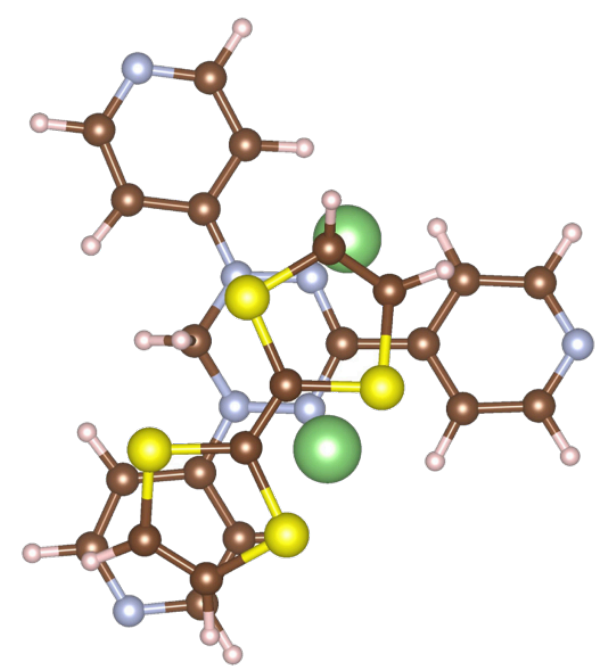

Figure S12. The DFT calculation of lithium atom binding energy with radical ligand $\mathbf{2}$ and TTF guests 4 (the structures are optimized during DFT calculation, details see computational method section). (a) first lithium atom binding $\left(E_{b}=2.67 \mathrm{eV}\right)$ and (b) second lithium atom binding $\left(E_{b}=1.69 \mathrm{eV}\right)$.

Reference:

(1) a) Busca, P.; Paradisi, F.; Moynihan, E.; Maguire, A. R.; Engle, P. C. Enantioselective Synthesis of Nonnatural Amino Acids Using Phenylalanine Dehydrogenases Modified by Site-directed Mutagenesis. Org. Biomol. Chem. 2004, 2, 2684-2691; b) Nakabayashi, K.; Ozaki, Y.; Kawano, M.; Fujita, M. A SelfAssembled Spin Cage. Angew. Chem. Int. Ed. 2008, 47, 2046-2048.

(2) Vanderbilt, D. Soft self-consistent pseudopotentials in a generalized eigenvalue formalism. Phys. Rev. B 1990, 41, 7892-7895.

(3) Blöchl, P.E. Projector augmented-wave method. Phys. Rev. B 1994, 50, 17953-17979.

(4) Perdew, J.P., Burke, K. \& Ernzerhof, M. Generalized Gradient Approximation Made Simple. Phys. Rev. Lett. 1996, 77, 3865-3868.

(5) Kresse, G. \& Hafner, J. Ab initiomolecular dynamics for liquid metals. Phys. Rev. B 1993, 47, 558-561. 